Article

\title{
Democratic Theory and the Potential of Value Frames in Assessing Media Performance
}

\author{
Ralph Weiß *, Raphael Kösters and Merja Mahrt \\ Institute of Social Sciences, Heinrich Heine University Düsseldorf, 40225 Düsseldorf, Germany; \\ E-Mails: ralph.weiss@phil.hhu.de (R.W.),raphael.koesters@phil.hhu.de (R.K.), mahrt@hhu.de (M.M.) \\ * Corresponding author
}

Submitted: 26 March 2020 | Accepted: 10 June 2020 | Published: 24 August 2020

\begin{abstract}
Media users need information and knowledge to act as free citizens. From this basic democratic assumption, news standards for media performance can be derived. Porto's (2007) model of the 'interpreting citizen' assigns a central role to the diversity of interpretive frames. These frames enable citizens to make judgments about societal issues and related political positions. However, a theoretical foundation for classifying these frames in terms of their content is missing. We propose to derive such a basis from democratic theories of citizenship, which assume that values define a citizen's position vis-à-vis the political sphere. Building on the cleavage approach from political science, we characterize which values organize political debates. The results of a large-scale content analysis of German news media demonstrate which empirical insights into media performance can be gained with a theoretically derived classification of value frames (most notably, measuring the substantive content of plurality). Based on this, we discuss additional avenues for future research.
\end{abstract}

\section{Keywords}

cleavages; citizenship; democracy; diversity; framing; media performance; news standards; plurality; political values

\section{Issue}

This article is part of the issue "Media Performance in Times of Media Change" edited by Melanie Magin (Norwegian University of Science and Technology, Norway) and Birgit Stark (Johannes Gutenberg University Mainz, Germany).

(C) 2020 by the authors; licensee Cogitatio (Lisbon, Portugal). This article is licensed under a Creative Commons Attribution 4.0 International License (CC BY).

\section{Introduction}

Theories of public opinion argue that democracy can function only through public communication of a certain quality, as public communication creates the conditions for citizens to act. Participatory approaches address this requirement explicitly by characterizing the function of public communication in a democracy as the 'empowerment' of citizens to exercise their political freedom (Ferree, Gamson, Gerhards, \& Rucht, 2002). Liberal approaches to public sphere theory additionally assume that public communication creates a 'marketplace of ideas' that allows citizens to form their own opinion and identify representations of their political stances. In this article, we discuss which performance public communication must provide to enable this type of active citizenship.
Porto (2007), based on his model of citizenship, defines plurality as a key indicator of media performance. He suggests operationalizing this well-established dimension of media performance (Christians, Glasser, McQuail, Nordenstreng, \& White, 2009) via measuring the diversity of interpretive frames. Following Porto, we argue that the communication of normative interpretations or viewpoints is central to how individual citizens process political issues and positions. However, our discussion of Porto's propositions reveals the need for a thorough theoretical foundation to adequately conceptualize the plurality of interpretive frames (Section 2). In Section 3, we introduce political values as a pivotal concept for such a classification of plurality. Political values and value conflicts (cleavages) shape a citizen's view of politics. Based on this understanding, we propose a concept for the empirical assessment of 'value frames,' that is, patterns 
of interpretation based on fundamental political values (Section 4). This approach is in line with different understandings of media diversity, which McQuail (1992) describes as "diversity as reflection" (p. 144) and "reflecting political divisions" (p. 163). Based on a large-scale content analysis of German news media, we then illustrate the capabilities of the proposed instrument for examining media performance.

The goal of the article is to demonstrate that value frames allow a detailed and theoretically grounded classification of the plurality of political positions across different issues. The measurement we propose extends previous approaches to capture plurality as a central indicator of media performance. Although the diversity of actors or topics is a manifest indicator of plurality that can be coded with relative ease (Jandura \& Friedrich, 2014; McQuail, 1992), it only indirectly reflects the substantive content of political positions, if at all. How media display actors or issues does not need to align with the diversity of political positions. It is possible, for instance, that the media cover only a limited spectrum of positions although a diversity of actors is mentioned (Baden \& Springer, 2017). Instead of using actors or issues as proxies for diversity, therefore, we propose to measure viewpoint diversity directly to advance the study of media performance in communication research. However, value frames thus also serve as an example of the integrative and interdisciplinary potential of media and communication studies. On the one hand, the proposed instrument builds on policy research, political sociology, and political psychology. On the other hand, these disciplines gain from studies of media performance that substantiate the importance of public communication for the functioning of democracy.

\section{Models of Citizenship and Standards of Media Performance}

Democratic theory forms the basis for research on media performance in communication studies, from which standards for assessing and classifying journalistic performance are derived. However, sometimes the respective notions of the role of the citizen remain implicit. A 2003 issue of Political Communication contained an explicit debate on such 'models' of citizenship. It includes Zaller (2003) building on Schudson's (1998) previous model of the 'monitorial citizen,' by combining it with a critique of standards for comprehensive and factual reporting. While emphasizing the historical and social contingency of these standards, Zaller agrees with Schudson in assuming that citizens must be able to critically overlook their political environment. Zaller postulates that citizens alternate between superficial knowledge of current events and an in-depth examination of only those issues that require their attention. Because attention plays a decisive role in this process, Zaller assigns journalism the task of providing a "burglar alarm" (p. 121) to draw attention.
Zaller's (2003) point of reference is the democratic principle that politicians must be held accountable by the citizenry. However, this accountability requires publicly available information on important issues. Such information should enable citizens to critically examine what politicians' activities mean for citizens and what deserves their attention. This raises the question of how this information must be shaped so that citizens can hold politicians accountable. Zaller's (2003) answer to this question focuses entirely on how attention can be attracted. His praise of alarmism as a function of journalism, however, ignores the obvious pitfalls of alarmist mediation versus an enlightened perception of politics. First, what is most sensational and draws attention is not necessarily the same as what is important, in the sense of being relevant to the social circumstances of life. A focus on the former would relieve politicians of the pressure to justify their actions and compromise citizens' ability to hold the politicians accountable. Second, the emotionalization and moralization typical of alarmist reporting would replace an informed representation of processes and positions. This would hinder citizens' ability to adequately assess what the positions or decisions of politicians mean for them (Bennett, 2003).

Porto (2007) seeks to overcome these limitations inherent in the model of the 'monitorial citizen,' without succumbing to the fiction of a citizen fully informed on all matters, either. Drawing from political psychology and the concept of civic competence, he discusses what kinds of information citizens need to perform their role competently. In his resulting model of the 'interpreting citizen,' he assigns a key role to the availability of 'interpretive frames' for "citizens' ability to interpret political reality in a consistent way" (p. 311). These interpretive frames enable an understanding of why events or processes are relevant for society. The frames offer an interpretation of the extent to which a problem affects the social and political life of a community, what defines the problem at its core, what causes the problem, who is responsible for it, and what measures should be used to solve the problem. Thus, Porto follows a general frame definition.

He emphasizes that such interpretations are expressed by 'sponsors' who promote specific perspectives on issues and events in public discourse. The resulting differences in the publicly available interpretations of political reality are based on diverging interests or points of view, which shape how a sponsor interprets an issue. Employees' or entrepreneurs' interpretations, for example, are likely to differ in what they see as the core of an issue such as digitization (e.g., job security versus profitability and security of investments) and what measures, therefore, are considered appropriate to resolve the issue. Thus, to enable citizenship in a free society, Porto $(2007$, p. 303) assumes that citizens must be able to perceive diverse competing interpretations of societal issues. Only the availability of such a plurality of interpretations enables citizens to form their own opinions and consequently, to perform their role competently. 
Plurality, as a necessary condition for the legitimacy of politics in a democracy, is a well-established standard for public discourse in the theory of the public sphere (Weiß et al., 2016). Porto (2007) transfers this idea from the macro-level to the level of individuals' competence to act. Again, he draws on an argument from political psychology that assumes that only examining diverse competing interpretations creates the basis for consistent judgment by individual citizens. This assumption is supported by research on framing effects (Sniderman \& Theriault, 2004). What is left unspoken by Porto and in framing research, however, is the difference between 'blind' followership of positions and informed partisanship that acknowledges alternatives, and thus, gains a deeper understanding of the meaning of the political positions. The latter is described by liberaldemocracy theorist Dahl (1989, p. 307) as an "enlightened understanding."

How can such an ideal be reached? On an individual level, examining diverse interpretive frames forms the basis of competent citizenship. At the societal level, this requires a media system that makes the pluralistic competition of political positions visible. To determine whether the media provide this plurality, interpretive frames must be defined and classified in a way that reveals which divergent viewpoints have entered the publicly available interpretation of reality. Porto (2007, p. 309), therefore, calls for framing analyses to unveil how the competition of interpretations is related to political power struggles. Such an analysis would necessitate a classification of interpretive frames that makes clear which respective position they support on a political issue. What is needed is a concept that describes the basic positions of political disputes in modern democracies and makes the positions identifiable via interpretive frames. We propose 'value frames' as such a concept. Value frames are patterns of interpretation based on fundamental political values and interpret issues or events in light of the latter (Ball-Rokeach \& Loges, 1996). These values affect which specific position is taken on controversial political issues.

To fulfill the analytical demands of Porto's model of the 'interpreting citizen,' two tasks arise from the previous considerations: First, the role of citizens in shaping the interpretive frames by which policies and politicians are judged must be clarified. This will further explain how central political values are to interpretive frames. Second, a classification of a potentially wide variety of competing interpretive frames must be developed.

\section{The Relevance of Political Values for Citizens' Perspectives}

When people use political ideologies (such as liberalism, socialism, or nationalism) or religious beliefs as the basis of their political stance, they are moving within systems of interpretation. This article is an attempt to describe which interpretive transitions are necessary to move from practical everyday experiences to the development of a political mode of interpretation. To determine what is important for people in their political role as citizens and therefore, what shapes their view of politics, interests related to practices of everyday life form the starting point. These interests vary with individuals' social situation (their interest in well-paid work or in a cheap labor force, their interest in affordable housing or in a return on property investments, their interest in unrestricted mobility or in an unpolluted environment, etc.).

Such interests reflect the options for and constraints on the success of an individual's life project. This perspective is necessarily egocentric, because the view of social conditions is determined by the question what these mean to the individual. This life-practical and interestrelated perspective of the private individual is separate from their role as a citizen.

In their daily life, citizens experience in numerous ways that their personal life project is dependent on social circumstances. Therefore, shaping these circumstances becomes part of their individual interests. However, the reflection of their personal situation and interests on the sphere of politics includes a transformation. Individual interests are transformed into demands for a system of rights and public services on which the scope and legitimacy of one's own interests depend. When the interests of different actors collide, the individual depends on the institutions of the rule of law to deal with and ideally resolve the collision of competing demands. Such individual interests additionally presuppose a public-service infrastructure, from public transportation to social housing to education, and much more.

This system of conditions for the realization of interests in societies is itself subject to change. The system is permanently transformed through the pressure of social demands. Such concrete demands represent an initial transformation of interests. Interests that are put forward as claims refer to the established or hoped-for general recognition of their validity within society. An interest becomes a claim by discursively and then practically incorporating it into a system of legally validatable claims. In political science, this transformation is analyzed when the role of parties in mediating between the concerns of citizens and the system of power that establishes rules of general validity is assessed. From this vantage point, parties are organs of 'interest aggregation': Through this aggregation, individual interests become part of a concept or program for harmonizing different interests and their interaction (see, for example, Lawson \& Poguntke, 2004). Although this integration entails the validation of some interests, it also limits their claim to validity in relation to others.

Citizens, therefore, must observe claims to political validity that reflect their interests. According to Faden-Kuhne (2012), citizens base this appraisal on their internalized normative values "to assess the positions of the parties on specific political issues or to determine 
whether the positions of the parties correspond to their own ideas" (p. 92, authors' translation). In practice, this assessment is already fully structured, as it takes place along established lines of conflict that can be characterized by maxims of good politics.

These maxims represent and articulate political values. Values are understood not as maxims by which individuals should conduct their lives, but as fundamental ideas about the organization of society (Feldman, 2003). Thus, values reflect social interests, but transform them into ideas about desirable social conditions that give validity to an individual's interests alongside those of other citizens. Therefore, a claim to societally shared values is not just a rhetorical technique. Even if seemingly instrumental and tactical, an appeal to values acknowledges that for claims to be justified, they must refer to some universally acceptable goal. Linking interests to values in this way changes their substance: Only if they appear to advance the success of living conditions in general can they expect recognition even from those who do not share the respective interests, but who would nevertheless be affected if these interests are met. Interest-based demands that allude to generalizable values, therefore, are an integral part of peaceful coexistence and conflict resolution in society.

Following these principles in public discourse does not end social conflicts, but it transforms the competition and conflict of social interests into a competition for implementing politics based on different normative principles. In modern democracies, this competition has been condensed into conflicts of political values that are established at various levels and thus, develop formative power. These lines of conflict are characterized by cleavages (Kitschelt, 1994; Lipset \& Rokkan, 1967).

To illustrate the basic ideas of cleavages, those present in Germany are given as an example. As in other Western societies (de Wilde, Koopmans, Merkel, Strijbis, \& Zürn, 2019), three fundamental lines of conflict characterize public discourse in Germany (Niedermayer, 2009). In the first socioeconomic axis of conflict, the ideal of a free market is opposed to an orientation toward welfarestate services. This line of conflict transforms the traditional class-based opposition of labor and capital into a dispute over the scope of state intervention in capitalist economies. Interests clash between the extremes of the individual pursuit of private success and social justice through collectively organized solidarity. The second sociocultural axis of conflict opposes libertarian to authoritarian positions. This dimension of conflict concerns the regulation of social order. One extreme position in this cleavage regards universal civil rights as the guiding principle of good politics. This position emphasizes participation and plurality, while the opposing pole insists on law and order being enforced by hierarchical authorities and sees conventional and conformist morality as binding. Grande and Kriesi (2012) have pointed out that these long-established dimensions of conflict are increasingly challenged by globalization, which has produced a third line of conflict. Divided between winners and losers of globalization, the first two cleavages are projected on an additionally fundamental question. It contrasts integrative positions, which advocate transnational political alliances and a multicultural composition of societies at the national level, with demarcating positions, which champion national sovereignty over international cooperation and insist on the ethnic homogeneity and demarcation of societies. This latter position is characteristic of right-wing populism and negates that which gives political dispute its potentially peacemaking function: the search for a common ground that integrates divergent points of view. This function translates conflicts into a question of 'more or less' regarding the social resources spent on different interpretations of a basic value such as 'justice' and to whom these interpretations are institutionally applied. The demarcation position, in contrast, promotes an ultimate identity conflict of 'either/or' in which only one's own position is recognized as legitimate, and opposing positions must be discredited, criminalized, and ultimately, overpowered.

How these cleavages as conflicts between fundamental political values shape public discourse can be determined at several interdependent levels. The cleavage concept originally identified social groups as sponsors of the basic political values that divide an axis of conflict. A social cleavage, thus, is understood as:

A deep-seated, robust, conflictual and, within the framework of the intermediary system, organizationally solidified line of conflict between social groups, which are defined by their socio-structural position and the material interests and political values derived from it, or primarily by their different values. (Niedermayer, 2009, p. 35, authors' translation)

Such groups form political milieus whose members share the same basic political values and thus, distinguish themselves from other milieus (Kösters \& Jandura, 2019). Political parties are the representatives and advocates of a milieu's understanding of good politics. How parties compete for the implementation of their political ideas can also be systematically characterized by their position in fundamental conflicts of values (Niedermayer, 2009, p. 37). From this point of view, parties ensure that the normative maxims of fundamental conflicts of values shape decision-making processes (Schön \& Rein, 1994). In their competition for power, parties present themselves in relation to fundamental values and thus, continually affirm them as important points of reference for the citizenry's formation of political opinions (Bartolini \& Mair, 1990). Last, conflicts of values are also reiterated by journalists who use the conflicts as schemata for presenting and evaluating political processes (Lee, McLeod, \& Shah, 2008).

Overall, public discourse is fundamentally structured by the three main axes of conflict. The conflict of political positions in the public sphere is carried out as a strug- 
gle of interpretive frameworks. In this struggle, actors interpret a given issue against the background of the normative value positions the actors represent and classify the issue by using respective value frames. Thus, public utterances contribute to the value frames competition (Scheufele \& Engelmann, 2013).

With the help of value frames, our initial question of what citizens should devote attention to can be answered. Citizens find themselves reflected in those value frames from public discourse that guide the citizens' own assessment and practical evaluation of politics. In this sense, Dahlgren (2005) sees values as the core of "civic cultures" (p. 18), that is, typical forms of citizenship that are rooted in real-world experiences. To enable citizenship through public communication, that and how guiding principles of good politics are affected by a given issue or proposal must be clear. For an informed understanding of politics, citizens must be able to discern what affects their own values, who stands up for the latter, who contradicts these values, what is or can be done to implement the values, etc. This must be made transparent through value frames in public interpretations of issues. Values from the opposing poles of the fundamental cleavages thus fill in what the evaluative interpretive frames in Porto's (2007) concept of the 'interpreting citizen' mean (see Section 2). In this sense, frames corresponding to the extremes of the axes of conflict provide a general basis for assessing media performance.

\section{Empirical Assessment and Classification of Value Frames along Cleavages}

Through value frames, a universal standard of democratic media performance can be analyzed: the diversity of political interpretations. Typically, the diversity of speakers is used as an indicator of diversity (Jandura \& Friedrich, 2014; McQuail, 1992), although it has its limitations as mentioned above (Baden \& Springer, 2017). With value frames, diversity of public discourse can be determined at the level of the content. As the opposing sides of cleavages reflect basic political values that shape attitudes on various issues, diversity can be determined not only in relation to single issues but also across different policy fields. Political scientists use the cleavage concept to characterize the heterogeneity of political positions in society, as well as between political parties. Adapting this concept for framing research in communication studies provides a direct avenue for analyzing to what degree political diversity in society and politics is made transparent by the media. Conversely, a cleavagebased analysis of value frames can offer political science insights into which political positions of social groups and political parties are represented in which media arenas.

Two extant studies follow this framework. Scheufele and Engelmann (2013) propose a measurement of value frames based on Porto's (2007) considerations. Regarding electoral debate, they state: "The media should rather communicate to voters which part of the value space is home to political parties and which coalitions of representation they therefore offer" (Scheufele \& Engelmann, 2013, p. 535, authors' translation, emphasis in original). To measure value frames, Scheufele and Engelmann follow the concept of 'master frames' (Benford \& Snow, 2000) and theoretically distinguish between cleavages. However, instead of sticking to the established cleavages from political sociology (see Section 3), the authors introduce a number of 'universal' as well as 'policy-field specific' values. Scheufele and Engelmann's distinction is not always straightforward (e.g., the distinction between 'solidarity' and 'justice' as universal values or between 'solidarity' as a universal value and 'state interventionism' as a value specific to a policy area).

In contrast, Höglinger, Wüest, and Helbling (2012) work with the original differentiation between the economic and cultural axes of conflict. The authors' definition of frames, however, focuses entirely on how the extremes of the respective conflicts align with the phenomenon of globalization, in line with their research question: "How do political actors justify the opposition and support of globalization?" (Höglinger et al., 2012, p. 229). Their content analysis stems from a research group studying the potentially formative power of the recently emerged cleavage between integration and demarcation for politics and public debate (Grande \& Kriesi, 2012). Because of this limited focus, Höglinger et al.'s (2012) operationalization cannot serve as a universal classification of issues.

The following proposal for measuring value frames in public discourse is intended as a solution to this problem. Closely following the definitions of the extremes of each of the three fundamental lines of conflicts from political sociology (see Table 1), this framework allows an assessment of the degree of diversity in news coverage-a central feature of media performance in democracies.

Value frames can be applied to the public discourse on various political issues: Regarding the environment and climate protection, for instance, the socioeconomic axis of conflict is particularly relevant. At one end of the spectrum, welfare state-oriented positions stress strict regulations to ensure that environmental damage does not impair the living conditions of current and future members of society. At the other end, market-liberal positions emphasize how environmental regulations impede economic growth. Balanced positions might argue for regulations that reward environmentally sustainable economic activities. On an issue such as assisted suicide, the sociocultural axis will likely be salient. Libertarian positions would champion the individual's right to decide matters of their own life, while an authoritarian position, depending on the cultural context, may favor the position of churches or other authorities that provide guidance about how lives should be lived-or ended. For some issues, more than one axis of conflict is pertinent. For climate protection, a position can combine, for example, statements that favor welfare state-oriented solu- 
Table 1. Fundamental value frames: Abridged version.

\begin{tabular}{|c|c|}
\hline Value frame & Description \\
\hline Market liberalism & $\begin{array}{l}\text { Guiding principle: Individual pursuit of economic success. } \\
\text { Policies should improve the conditions of business activities, but refrain from regulation. } \\
\text { Individual economic effort is preferred over compensation for disadvantages. }\end{array}$ \\
\hline Welfare state orientation & $\begin{array}{l}\text { Guiding principle: Participation by all members of society in economic welfare and social } \\
\text { and cultural life. } \\
\text { Policies should guarantee the welfare of all members of society and enable dignified living } \\
\text { conditions. Restrictive regulation of private businesses is necessary to share burdens. }\end{array}$ \\
\hline Libertarianism & $\begin{array}{l}\text { Guiding principle: Respect for the freedom and self-determination of the individual. } \\
\text { Policies should guarantee the right to individual self-determination and to democratic } \\
\text { participation, for all human beings. }\end{array}$ \\
\hline Authoritarianism & $\begin{array}{l}\text { Guiding principle: Respect for order and traditions of decency. } \\
\text { The basis for legitimate membership in the political community is a moral community based } \\
\text { on tradition and genealogy. Policies should uphold traditions and enable the unchallenged } \\
\text { enforcement of the legal order. }\end{array}$ \\
\hline Integration & $\begin{array}{l}\text { Guiding principle: Problems and conflicts are solved through cooperation and compromise. } \\
\text { Democracy and human rights are regarded as the basis of political communities. Cooperation } \\
\text { between individuals, regions, and nations is the preferred way to solve problems. }\end{array}$ \\
\hline Demarcation & $\begin{array}{l}\text { Guiding principle: Problems and conflicts are managed by the people uniting and the nation } \\
\text { standing its ground against adversaries. } \\
\text { The political community is understood as a fighting unit that needs to establish its national } \\
\text { unity internally and assert its interests externally. Cultural and political processes should } \\
\text { contribute to establishing identification with the nation. }\end{array}$ \\
\hline
\end{tabular}

Note: The full description of value frames is included in the Supplementary File that also contains coding instructions and examples.

tions with international cooperation. Thus, value frames are comparatively universal indicators of media diversity as the frames transcend issues, while providing more information than the mere number of different speakers.

\section{Empirical Insights into Media Performance Through Value Frames}

We illustrate the benefits of an analysis of value frames in public discourse through findings from a large-scale content analysis. Selected findings are presented below to demonstrate the capabilities of an analysis of value frames to assess media performance. For this article, 5,279 content items from 16 German media outlets (print, television, radio, and online) were analyzed. The sample consists of media outlets that represent different types of German news media: Die Zeit and Der Spiegel (weekly magazines), FAZ, SZ (quality daily newspapers, conservative and liberal, respectively), Bild (tabloid press), Rheinische Post (regional daily), taz and Junge Freiheit (print outlets targeting the left and right fringes of the political spectrum, respectively), Tagesschau, WDR aktuell (public service television and radio news), RTL aktuell (commercial television news), spiegel.de, faz.net, bild.de, and tagesschau.de (online equivalents of the respective outlets), and t-online.de (online news portal). The content analysis comprises four periods of inquiry in 2018 (26 May-15 June, 29 June-5 July, 17 September-
7 October, 22 October-28 October). To avoid event- or issue-related bias, this selection includes parliamentary sitting weeks as well as non-sitting weeks. The data are based on a random sample of all published articles that focus on national politics, the filter criterion (sampling error between $3 \%$ and $5 \%$, except for a full survey of Die Zeit, Der Spiegel, Junge Freiheit, Tagesschau, RTL aktuell, and bild.de). For each article, the value frames of up to three actors are coded. For each actor and for each cleavage, coders assess whether the actor favors one side, whether the actor takes up a balanced position, or whether there is no cleavage reference (see the Supplementary File for the coding instructions). Despite the relatively high level of abstractness of value frames, the coding reliability across coders reached acceptable levels (Brennan and Prediger's kappa between 0.8 and 0.9 ).

\subsection{The Share of Value Frames in News Content as a Prerequisite of Comprehension}

As discussed above, Porto (2007) argues that citizens require media to make transparent how political processes and proposals relate to fundamental values. Therefore, in the first step, we determine the extent to which different types of media display value frames (Table 2). Quality daily and weekly print media as well as public-service TV news provide users with the most extensive overview 
Table 2. Proportion of articles with value frames.

\begin{tabular}{lcc}
\hline Media outlet & Total number of articles $(n)$ & Share of articles with value frames $(\%)$ \\
\hline Die Zeit & 117 & 47.9 \\
Tagesschau & 193 & 44.0 \\
Der Spiegel & 149 & 42.3 \\
FAZ & 619 & 40.2 \\
tagesschau.de & 487 & 39.6 \\
SZ & 576 & 38.0 \\
t-online.de & 286 & 35.3 \\
spiegel.de & 594 & 35.2 \\
faz.net & 491 & 34.8 \\
Rheinische Post & 256 & 34.0 \\
taz & 282 & 33.3 \\
RTL aktuell & 183 & 32.8 \\
bild.de & 441 & 29.5 \\
Junge Freiheit & 180 & 29.4 \\
Bild & 264 & 27.3 \\
WDR aktuell & 161 & 23.6 \\
\hline Total & 5,279 & 35.6 \\
\hline
\end{tabular}

Note: Cramér's V = 0.1.

of normative frames that shape debates. The tabloid Bild and news from commercial television program RTL provide less transparency of normative positions. Media that function as a forum for extreme political camps (such as the right-wing Junge Freiheit) likewise rarely contain value frames. Their high frequency (and therefore, the high level of normative transparency) in the public broadcaster Tagesschau, at the other end of the spectrum, is remarkable, especially as its 15 -minute format is restrictive when compared to broadsheets like Die Zeit, $S Z$, or FAZ. Articles on the online edition tagesschau.de also frequently contain value frames. Thus, public television news is characterized by its extensive efforts to ensure the transparency of normative positions.

\subsection{Plurality in the Mediation of Value Frames}

The mere frequency of value frames in news is not the only indicator of media performance. Citizens should also be able to assess the breadth of a debate and the different positions expressed on a given issue. Plurality, therefore, is a necessary requirement, not only on the individual but also on the systemic level. Value frames allow characterization of how diverse specific issues or larger policy areas appear in media coverage. Such an analysis provides an avenue for assessing media performance as required by liberal concepts of the public sphere, according to the idea of a 'marketplace of ideas.' Through value frames, plurality cannot only be measured by the diversity of speakers in a debate but also captured directly via the normative foundations of publicly visible policy concepts.

To illustrate the insight into plurality enabled by value frames, their diversity is presented for two policy areas as apparent in the coverage of the quality papers $F A Z$ and $S Z$. For one of the dominant topics in 2018, migration, a comparison of the two papers reveals that they emphasize integrative and demarcating frames to an almost equal degree (Table 3). A similar picture emerges for their reporting on the broader field of economic issues, where market-liberal and welfare state-oriented frames are balanced (Table 4). FAZ additionally presents frames that advocate free transnational economic relations (integration) over national-state protectionist ones (demarcation), while the reporting in $S Z$ reverses the emphases.

The prominence of value frames thus differs in two respects for the selected policy fields: First, different axes of conflict are relevant for each policy field. In the case of migration, the conflict is between integration and demarcation, and for economic issues, mainly the socioe-

Table 3. Coverage of the issue of migration: Distribution of value frames in quality newspapers.

\begin{tabular}{lccccccccc}
\hline & & \multicolumn{2}{c}{ Libertarianism } & \multicolumn{2}{c}{ Authoritarianism } & \multicolumn{2}{c}{ Integration } & \multicolumn{2}{c}{ Demarcation } \\
\cline { 3 - 9 } Media outlet/frame & $n$ (statements) & $\%$ & Diff. to avg. & $\%$ & Diff. to avg. & $\%$ & Diff. to avg. & $\%$ & Diff. to avg. \\
\hline FAZ & 62 & 1.6 & -3.2 & 1.6 & -4.0 & 48.4 & 2.4 & 48.4 & 6.3 \\
SZ & 54 & 3.7 & -1.1 & 3.7 & -1.9 & 40.7 & -5.3 & 51.9 & 9.8 \\
\hline All media & 605 & 4.8 & & 5.6 & & 46.0 & & 42.1 & \\
\hline
\end{tabular}

Note: Cramér's V = 0.1. 
Table 4. Coverage of economic issues: Distribution of value frames in quality newspapers.

\begin{tabular}{|c|c|c|c|c|c|c|c|c|c|c|c|c|c|}
\hline \multirow[b]{2}{*}{$\begin{array}{l}\text { Media } \\
\text { outlet/frame }\end{array}$} & \multirow[b]{2}{*}{$\begin{array}{c}n \\
\text { (statements) }\end{array}$} & \multicolumn{2}{|c|}{$\begin{array}{c}\text { Market } \\
\text { liberalism }\end{array}$} & \multicolumn{2}{|c|}{$\begin{array}{c}\text { Welfare state } \\
\text { orientation }\end{array}$} & \multicolumn{2}{|c|}{ Libertarianism } & \multicolumn{2}{|c|}{ Authoritarianism } & \multicolumn{2}{|c|}{ Integration } & \multicolumn{2}{|c|}{ Demarcation } \\
\hline & & $\%$ & $\begin{array}{l}\text { Diff. } \\
\text { to avg. }\end{array}$ & $\%$ & $\begin{array}{l}\text { Diff. } \\
\text { to avg. }\end{array}$ & $\%$ & $\begin{array}{l}\text { Diff. } \\
\text { to avg. }\end{array}$ & $\%$ & $\begin{array}{l}\text { Diff. } \\
\text { to avg. }\end{array}$ & $\%$ & $\begin{array}{l}\text { Diff. } \\
\text { to avg. }\end{array}$ & $\%$ & $\begin{array}{l}\text { Diff. } \\
\text { to avg. }\end{array}$ \\
\hline$F A Z$ & 79 & 31.6 & 5.0 & 32.9 & -4.5 & 3.8 & -1.1 & - & - & 20.3 & 0.3 & 11.4 & 2.0 \\
\hline$S Z$ & 37 & 27.0 & 0.4 & 29.7 & -7.7 & 2.7 & -2.2 & - & - & 16.2 & -3.8 & 24.3 & 14.9 \\
\hline All media & 350 & 26.6 & & 37.4 & & 4.9 & & - & & 20.0 & & 9.4 & \\
\hline
\end{tabular}

Note: Cramér's V $=0.2$.

conomic axis of conflict as well as integration versus demarcation. Second, which value frames a medium emphasizes, therefore, can differ from issue to issue. For this reason, it makes sense to examine the plurality of news coverage separately by policy field or topical area.

Plurality of news coverage can further be assessed through the degree to which competing normative frames (such as a market-liberal and a welfare-state perspective) are presented in the same article. Across all topics and news outlets, such a dialogical presentation of conflicting positions within the same article rarely occurs (in about one fifth of the articles; Table 5). Again, with the exception of news from public-service radio WDR aktuell, news from public-service broadcasting provides above-average performance. For the other media, no clear hierarchy emerges. Presenting competing value frames within one article is a parsimonious way to ensure plurality. However, the media can, of course, also establish a 'marketplace of ideas' by representing competing positions in separate articles. An analysis by issue or policy area as presented in Table 3 and Table 4 allows an assessment of this form of plurality.

\subsection{The Media's Emphasis on Political Values: Editorial Lines}

In addition to reporting on the positions of political actors, the media play an active role in the process of opinion building in society. They take positions in opinion pieces and editorials (Eilders, 2002) and by systematically favoring selected political positions in their reporting (Kepplinger, Brosius, \& Staab, 1991). Taken together, this makes up the media's 'editorial line.' Measuring value frames allows a precise diagnosis of these lines.

After examining specific issues and policy areas in the previous section, our focus shifts back to the overall news coverage of each outlet. We examine the chances each value frame has of being reflected in the selected media. The following media-specific patterns of value frames emerge: 1) The conservative $F A Z$ and the liberal $S Z$ are similar in their emphasis on libertarian versus authoritarian positions. However, they differ significantly in the weight they award to welfare state positions. These clearly dominate market-liberal positions in $S Z$, while the relationship is more balanced in FAZ; 2 ) the tabloid Bild

Table 5. Proportion of articles with opposing positions.

\begin{tabular}{lcc}
\hline Media outlet & Number of articles with value frames $(n)$ & Share of articles with opposing positions \\
\hline Tagesschau & 85 & 27.1 \\
Der Spiegel & 63 & 25.4 \\
RTL aktuell & 60 & 25.0 \\
tagesschau.de & 193 & 24.4 \\
Die Zeit & 56 & 23.2 \\
t-online.de & 101 & 22.8 \\
Bild & 72 & 22.2 \\
FAZ & 249 & 22.1 \\
faz.net & 171 & 20.5 \\
bild.de & 130 & 18.5 \\
WDR aktuell & 38 & 18.4 \\
SZ & 219 & 17.8 \\
Rheinische Post & 87 & 17.2 \\
spiegel.de & 209 & 17.2 \\
Junge Freiheit & 53 & 11.3 \\
taz & 94 & 5.3 \\
\hline Total & 1,880 & 19.9 \\
\hline
\end{tabular}

Note: Cramér's V = 0.1. 
Table 6. Distribution of value frames depending on the medium.

\begin{tabular}{|c|c|c|c|c|c|c|c|c|c|c|c|c|c|}
\hline \multirow[b]{2}{*}{$\begin{array}{l}\text { Media } \\
\text { outlet/frame }\end{array}$} & \multirow[b]{2}{*}{$\begin{array}{c}n \\
\text { (statements) }\end{array}$} & \multicolumn{2}{|c|}{$\begin{array}{c}\text { Market } \\
\text { liberalism }\end{array}$} & \multicolumn{2}{|c|}{$\begin{array}{c}\text { Welfare state } \\
\text { orientation }\end{array}$} & \multicolumn{2}{|c|}{ Libertarianism } & \multicolumn{2}{|c|}{ Authoritarianism } & \multicolumn{2}{|c|}{ Integration } & \multicolumn{2}{|c|}{ Demarcation } \\
\hline & & $\%$ & $\begin{array}{c}\text { Diff. } \\
\text { to } \\
\text { avg. }\end{array}$ & $\%$ & $\begin{array}{c}\text { Diff. } \\
\text { to } \\
\text { avg. }\end{array}$ & $\%$ & $\begin{array}{c}\text { Diff. } \\
\text { to } \\
\text { avg. }\end{array}$ & $\%$ & $\begin{array}{c}\text { Diff. } \\
\text { to } \\
\text { avg. }\end{array}$ & $\%$ & $\begin{array}{c}\text { Diff. } \\
\text { to } \\
\text { avg. }\end{array}$ & $\%$ & $\begin{array}{c}\text { Diff. } \\
\text { to } \\
\text { avg. }\end{array}$ \\
\hline$F A Z$ & 364 & 11.0 & 3.5 & 17.9 & 2.7 & 12.4 & -1.3 & 4.1 & -1.4 & 37.1 & -0.2 & 17.6 & -3.3 \\
\hline$S Z$ & 300 & 7.7 & 0.2 & 20.0 & 4.8 & 12.0 & -1.7 & 2.3 & -3.2 & 36.7 & -0.4 & 21.3 & 0.4 \\
\hline Der Spiegel & 82 & 17.1 & 9.6 & 15.9 & 0.7 & 15.9 & 2.2 & 7.3 & 1.8 & 29.3 & -8.0 & 14.6 & -6.3 \\
\hline Die Zeit & 75 & 6.7 & -0.8 & 12.0 & -3.2 & 12.0 & -1.7 & 4.0 & -1.5 & 37.3 & 0.0 & 28.0 & 7.1 \\
\hline Bild & 95 & 8.4 & 0.9 & 12.6 & -2.6 & 10.5 & -3.2 & 11.6 & 6.1 & 27.4 & -9.9 & 29.5 & 8.6 \\
\hline Junge Freiheit & 65 & 1.5 & -6.0 & 3.1 & -12.1 & 15.4 & 1.7 & 4.6 & -0.9 & 40.0 & 2.7 & 35.4 & 14.5 \\
\hline $\operatorname{taz}$ & 110 & 4.5 & -3.0 & 21.8 & 6.6 & 28.2 & 14.5 & 3.6 & -1.9 & 26.4 & -10.9 & 15.5 & -5.4 \\
\hline Rheinische Post & 99 & 8.1 & 0.6 & 28.3 & 13.1 & 18.2 & 4.5 & 7.1 & 1.6 & 30.3 & -7.0 & 8.1 & -12.8 \\
\hline Tagesschau & 125 & 12.0 & 4.5 & 14.4 & -0.8 & 11.2 & -2.5 & 2.4 & -3.1 & 37.6 & 0.3 & 22.4 & 1.5 \\
\hline RTL aktuell & 85 & 4.7 & -2.8 & 16.5 & 1.3 & 9.4 & -4.3 & 7.1 & 1.6 & 36.5 & -0.8 & 25.9 & 5.0 \\
\hline WDR aktuell & 52 & 5.8 & -1.7 & 25.0 & 9.8 & 1.9 & -11.8 & 5.8 & 0.3 & 42.3 & 5.0 & 19.2 & -1.7 \\
\hline bild.de & 169 & 8.9 & 1.4 & 10.1 & -5.1 & 14.8 & 1.1 & 6.5 & 1.0 & 37.9 & 0.6 & 21.9 & 1.0 \\
\hline faz.net & 239 & 8.4 & 0.9 & 16.7 & 1.5 & 13.4 & -0.3 & 6.7 & 1.2 & 36.4 & -0.9 & 18.4 & -2.5 \\
\hline spiegel.de & 282 & 3.5 & -4.0 & 9.9 & -5.3 & 13.8 & 0.1 & 7.1 & 1.6 & 41.5 & 4.2 & 24.1 & 3.2 \\
\hline tagesschau.de & 285 & 4.6 & -2.9 & 12.3 & -2.9 & 13.3 & -0.4 & 7.0 & 1.5 & 44.9 & 7.6 & 17.9 & -3.0 \\
\hline t-online.de & 134 & 5.2 & -2.3 & 8.2 & -7.0 & 15.7 & 2.0 & 4.5 & -1.0 & 38.1 & 0.8 & 28.4 & 7.5 \\
\hline Total & 2,561 & 7.5 & & 15.2 & & 13.7 & & 5.5 & & 37.3 & & 20.9 & \\
\hline
\end{tabular}

Notes: Cramér's V $=0.1$. Differences of more than $+/-5 \%$ from the overall average are indicated in bold.

stands out with its high proportion of authoritarian positions, which is more than twice as high as the average of the sample as a whole; and 3) media outlets on the fringes of the political spectrum put forward value frames that correspond to the outlets' particular political profile in the media market. In taz, libertarian positions are strongly pronounced, while demarcating positions are more prominent in Junge Freiheit than in any other outlet (Table 6).

Thus, the analysis uncovers the preferred political values of each medium, reflecting their 'editorial line,' that is, the active position of the media in political debates. An analysis of three dimensions of value frames is clearly more precise than the positioning on the left-right axis found in previous studies. Value frames indicate in a differentiated manner which normative positions are favored in each medium. Such an analysis of media coverage is also more comprehensive than an analysis of editorials or of individual controversial issues alone.

\section{Conclusions: Value Frames as a Key to Media Performance}

The analysis of value frames in public discourse provides a tool for assessing to what extent mediated public communication provides users with a basis for evaluating politics as citizens of a liberal democracy. How media communicate value frames is crucial to the meaning that 'interpreting citizens' assign to the mediated portrayals of politics. Media lay the foundation for the orientation of the citizenry regarding their basic understanding of good politics - and who represents them or opposes them.

To the extent that the media present competing value frames for a given area of politics, the media also fulfill their role as providers of a 'marketplace of ideas' to different degrees. Value frames allow a direct classification of the substantive content of plurality. They provide information about the extent of plurality for specific issues and across policy fields. Thus, value frames are suited for dealing with the core dimensions of theories of the public sphere.

Limitations concerning the explanatory power of value frames in characterizing political positions result from shifts in the political lines of conflict. For example, right-wing populist actors link the demand for more participation, which thus far has been defined as a libertarian position on the sociocultural axis of conflict, with law and order positions that mark the opposite pole. Such discursive shifts make it necessary to continuously monitor the applicability of conflict positions and adjust them if necessary. Value frames reflect basic political positions in political statements. Thus, the frames do not include all aspects of political positions (such as pragmatic or efficiency-oriented evaluations). However, the value frames describe a central part of the political discourse that emphasizes the forum function of the media.

In addition to characterizing the media's role as a 'marketplace of ideas,' value frames provide an additional approach for journalism research. The 'editorial line' of media outlets can be characterized more pre- 
cisely by their position on the axes of conflict that fundamentally structure the political debate. The position of a medium can also be specified in a more differentiated manner for specific policy areas or sections of an outlet. In this way, the inner heterogeneity and diversity of editorial work are uncovered.

Although the present article is limited to an analysis of media coverage at the level of outlets and topics, value frames can be applied in additional ways. One extension concerns an actor-based coding of value frames. If the positions of specific political actors (individuals or organizations) on a given issue are expressed in an article, the value frames inherent in the respective statements can be attributed to the actor. This allows an analysis of mediated portrayals of political actors and their own positioning in different policy areas. For political parties, such an analysis can be compared to classifications of party positions from political science (Franzmann \& Kaiser, 2006). Thus, value frames provide an avenue for studying the so-called 'media-party parallelism' (van Kempen, 2007). This provides insights into the different chances of parties for public resonance, that is, their ability to communicate their normative positions in different media arenas.

Value frames also form a bridging concept for analyzing political milieus in political sociology. Content analyses of value frames provide information about the extent to which the political values typical of a given milieu are represented in public discourse. Furthermore, it can be shown which medium acts as a forum for which specific milieus. Thus, communication studies can contribute to the ongoing debate in political science of a 'crisis of representation' (Linden \& Thaa, 2011). The inclusion of milieus in the process of opinion-building depends on the public representation of milieu-specific political values. Therefore, an analysis of media performance through value frames can contribute to an understanding of the role of the media in political integration or the fragmentation of societies. Thus, value frames are useful for dealing with a range of questions related to democratic theory on the role of the media in political processes.

\section{Acknowledgments}

The research project 'Media Performance \& Democracy' is funded by the German Research Foundation (DFG, project number 323375807), the Austrian Science Fund (FWF, project number 3155 ) and the Swiss National Science Foundation (SNF, project number 10001CE170784). The collection of the data underlying the analyses was coordinated and supervised by Miriam Steiner, Andrea Häuptli, and Andreas Riedl.

\section{Conflict of Interests}

The authors declare no conflict of interests.

\section{Supplementary Material}

Supplementary material for this article is available online in the format provided by the authors (unedited).

\section{References}

Baden, C., \& Springer, N. (2017). Conceptualizing viewpoint diversity in news discourse. Journalism, 18, 176-194.

Ball-Rokeach, S. J., \& Loges, W. E. (1996). Making choices: Media roles in the construction of value-choices. In C. Seligman, J. M. Olson, \& M. P. Zanna (Eds.), The Ontario symposium: The psychology of values (Vol. 8, pp. 277-298). Mahwah, NJ: Erlbaum.

Bartolini, S., \& Mair, P. (1990). Identity, competition, and electoral availability: The stabilisation of European electorates 1885-1985. Cambridge: Cambridge University Press.

Benford, R. D., \& Snow, D. A. (2000). Framing processes and social movements: An overview and assessment. Annual Review of Sociology, 26, 611-639.

Bennett, L. W. (2003). The burglar alarm just keeps ringing: A response to Zaller. Political Communication, 20, 131-138.

Christians, C. G., Glasser, T. L., McQuail, D., Nordenstreng, K., \& White, R. A. (2009). Normative theories of the media: Journalism in democratic societies. Urbana, IL: University of Illinois Press.

Dahl, R. A. (1989). Democracy and its critics. New Haven, CT: Yale University Press.

Dahlgren, P. (2005). The Internet, public spheres, and political communication: Dispersion and deliberation. Political Communication, 22, 147-162.

de Wilde, P., Koopmans, R., Merkel, W., Strijbis, O., \& Zürn, M. (Eds.). (2019). The struggle over borders: Cosmopolitanism and communitarianism. Cambridge: Cambridge University Press.

Eilders, C. (2002). Conflict and consonance in media opinion: Political positions of five Germany quality newspapers. European Journal of Communication, 17, 25-63.

Faden-Kuhne, K. (2012). Neuere Ansätze in der Wahlforschung: Heuristiken und Emotionen [Newer approaches in election research: Heuristics and emotions]. In O. W. Gabriel \& B. Westle (Eds.), Wählerverhalten in der Demokratie: Eine Einführung [Electoral behavior in democracy: An introduction] (pp. 87-115). Baden-Baden: Nomos.

Feldman, S. (2003). Values, ideology, and the structure of political attitudes. In D. Sears, L. Huddy, \& R. Jervis (Eds.), Handbook of political psychology (3rd ed., pp. 477-508). Oxford: Oxford University Press.

Ferree, M. M., Gamson, W. A., Gerhards, J., \& Rucht, D. (2002). Four models of the public sphere in modern democracies. Theory and Society, 31, 289-324.

Franzmann, S., \& Kaiser, A. (2006). Locating political parties in policy space. Party Politics, 12, 163-188. 
Grande, E., \& Kriesi, H. (2012). The transformative power of globalization and the structure of political conflict in Western Europe. In H. Kriesi, E. Grande, M. Dolezal, M. Helbling, D. Höglinger, S. Hutter, \& B. Wüest (Eds.), Political conflict in Western Europe (pp. 3-35). Cambridge: Cambridge University Press.

Höglinger, D., Wüest, B., \& Helbling, M. (2012). Culture versus economy: The framing of public debates over issues related to globalization. In H. Kriesi, E. Grande, M. Dolezal, M. Helbling, D. Höglinger, S. Hutter, \& B. Wüest (Eds.), Political conflict in Western Europe (pp. 229-253). Cambridge: Cambridge University Press.

Jandura, O., \& Friedrich, K. (2014). The quality of political media coverage. In C. Reinemann (Ed.), Political communication (pp. 351-373). Berlin: deGruyter.

Kepplinger, H. M., Brosius, H.-B., \& Staab, J. F. (1991). Instrumental actualization: A theory of mediated conflicts. European Journal of Communication, 6, 263-290.

Kitschelt, H. (1994). The transformation of European social democracy. Cambridge: Cambridge University Press.

Kösters, R., \& Jandura, O. (2019). A stratified and segmented citizenry? Identification of political milieus and conditions for their communicative integration. Javnost: The Public, 26, 33-53.

Lawson, K., \& Poguntke, T. (Eds.). (2004). How political parties respond: Interest aggregation revisited. London: Routledge.

Lee, N.-J., McLeod, D. M., \& Shah, D. V. (2008). Framing policy debates: Issue dualism, journalistic frames, and opinions on controversial policy issues. Communication Research, 35, 695-718.

Linden, M., \& Thaa, W. (2011). Krise und Repräsentation [Crisis and representation]. In M. Linden \& W. Thaa (Eds.), Krise und Reform politischer Repräsentation [Crisis and reform of political representation] (pp. 11-41). Baden-Baden: Nomos.

Lipset, S. M., \& Rokkan, S. (1967). Cleavage structures, party systems and voter alignments. In S. M. Lipset \& S. Rokkan (Eds.), Party systems and voter alignments: Cross-national perspectives (pp. 1-64). New York, NY: Free Press.

McQuail, D. (1992). Media performance: Mass communication and the public interest. London: Sage.

Niedermayer, O. (2009). Gesellschaftliche und parteipoli- tische Konfliktlinien [Societal and party-related cleavages]. In S. Kühnel, O. Niedermayer, \& B. Westle (Eds.), Wähler in Deutschland [Voters in Germany] (pp. 30-67). Wiesbaden: VS Verlag.

Porto, M. P. (2007). Frame diversity and citizen competence: Towards a critical approach to news quality. Critical Studies in Media Communication, 24, 303-321.

Scheufele, B., \& Engelmann, I. (2013). Die publizistische Vermittlung von Wertehorizonten der Parteien: Normatives Modell und empirische Befunde zum ValueFraming und News Bias der Qualitäts: und Boulevardpresse bei vier Bundestagswahlen [How media transmit the values of political parties: Normative model and empirical results in value framing and news biases of the quality and tabloid press for four federal parliamentary elections]. Medien und Kommunikationswissenschaft, 61, 532-550.

Schön, D., \& Rein, M. (1994). Frame reflection: Toward the resolution of intractable policy controversies. New York, NY: Basic Books.

Schudson, M. (1998). The good citizen. New York, NY: Free Press.

Sniderman, P. M., \& Theriault, S. M. (2004). The structure of political argument and the logic of issue framing. In W. E. Saris \& P. M. Sniderman (Eds.), Studies in public opinion: Attitudes, nonattitudes, measurement error, and change (pp. 133-165). Princeton, NJ: Princeton University Press.

van Kempen, H. (2007). Media-party parallelism and its effects: A cross-national comparative study. Political Communication, 24, 303-320.

Weiß, R., Magin, M., Hasebrink, U., Jandura, O., Seethaler, J., \& Stark, B. (2016). Publizistische Qualität im medialen Wandel: Eine normativ begründete Standortbestimmung [Journalistic quality in media change: A normative perspective]. In P. Werner, L. Rinsdorf, T. Pleil, \& K.-D. Altmeppen (Eds.), Verantwortung-Gerechtigkeit-Öffentlichkeit: Normativität in den Medien und in der Kommunikationswissenschaft [Responsibility-fairness-public sphere: Normativity in media and in communication studies] (pp. 27-49). Konstanz: UVK.

Zaller, J. (2003). A new standard of news quality: Burglar alarms for the monitorial citizen. Political Communication, 20, 109-130.

\section{About the Authors}

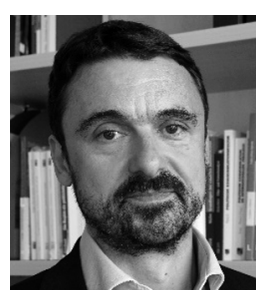

Ralph Weiß studied psychology at the University of Hamburg, where he also completed his 'Habilitation' in communication science/journalism. He was a Research Associate at the Hans Bredow Institute for Media Research, University of Hamburg, before he became Full Professor of Communication and Media Studies at the Heinrich Heine University Düsseldorf in 2003. His main research interests are political communication, media performance and democracy, as well as the praxeology of media use. 


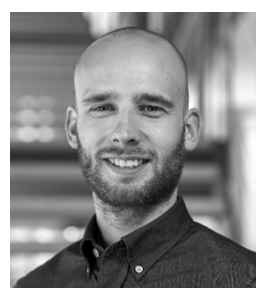

Raphael Kösters works as a Research Associate at the Institute of Social Sciences of the Heinrich Heine University Düsseldorf. He studied political science and communication studies in Mannheim, Budapest, and Düsseldorf. His main research interests are media and political sociology, political communication, and media content analyses. He received his PhD from the University of Düsseldorf with a thesis on the media's portrayal of migration as a key issue in current political debate and its implications for the political integration of society.

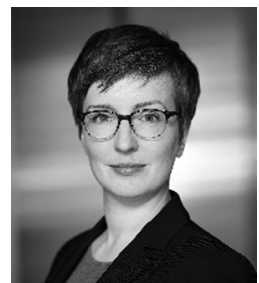

Merja Mahrt studied communication and media at Freie Universität Berlin. She received her PhD from the University of Amsterdam and finished her 'Habilitation' at the Heinrich Heine University Düsseldorf, where she is a Research Associate. Her research focuses on social functions and effects of media and their use. In 2019, she published Beyond Filter Bubbles and Echo Chambers: The Integrative Potential of the Internet, an open-access book on digital fragmentation and differences between online and offline media for social integration. (Photo by Alexander Vejnovic). 